\title{
SEXUAL VIOLENCE PREVENTION THROUGH BYSTANDER EDUCATION: AN EXPERIMENTAL EVALUATION
}

\author{
Victoria L. Banyard, Mary M. Moynihan, and \\ Elizabethe G. Plante
}

University of New Hampshire

\begin{abstract}
The current study used an experimental design to evaluate a sexual violence prevention program based on a community of responsibility model that teaches women and men how to intervene safely and effectively in cases of sexual violence before, during, and after incidents with strangers, acquaintances, or friends. It approaches both women and men as potential bystanders or witnesses to behaviors related to sexual violence. Three hundred and eighty-nine undergraduates participated and were randomly assigned to one of two treatment groups or a control group. Results from the research reveal that up to 2 months after participating in either a one-or three-session version of the program, participants in the treatment conditions showed improvements across measures of attitudes, knowledge, and behavior while the control group did not. Most program effects persisted at 4- and 12-month follow-ups. The program appeared to benefit both women and men. Implications and future directions for research are discussed. (c) 2007 Wiley Periodicals, Inc.
\end{abstract}

A variety of research studies document the problem of sexual violence for college-age samples, with lifetime incidence rates for college women of $50 \%$ or more and academic year prevalence rates of 20\% (e.g., Banyard, Plante, Ward, Cohn, Moorhead, \& Walsh, 2005; Fisher, Cullen, \& Turner, 2000; Himelein, 1995; Koss, Gidycz, \& Wisniewski, 1987). Exposure to sexual assault has been associated with a variety of negative mental health outcomes across types of samples and communities (e.g., Acierno, Brady, Gray, Kilpatrick, Resnick, \& Best, 2002; Banyard, Williams, \& Siegel, 2001;

This project was supported by Grant No. 2002-WG-BX-0009 awarded by the National Institute of Justice, Office of Justice Programs, U.S. Department of Justice. Points of view in this document are those of the authors and do not necessarily represent the official position or policies of the U.S. Department of Justice. Correspondence to: Victoria L. Banyard, Ph.D., Department of Psychology, University of New Hampshire, 10 Library Way, Durham, NH 03824. E-mail: victoria.banyard@unh.edu 
Brener, McMahon, Warren, \& Douglas, 1999; Campbell \& Soeken, 1999). The empirical literature also contains many accounts of rape prevention programs that target both men and women (e.g., Heppner, Humphrey, Hillenbrand-Gunn, \& Debord, 1995; Lanier, Elliott, Martin, \& Kapadia, 1998; Lonsway \& Kothari, 2000; Pinzone-Glover, Gidycz, \& Jacobs, 1998) and those that focus on men in particular (e.g., Foubert \& McEwen, 1998; Schewe \& O'Donohue, 1996). Rooted in theories of community responsibility and prosocial bystander behavior, the current study empirically evaluated the effectiveness of teaching prevention to individuals as potential bystanders rather than solely as potential perpetrators or victims.

\section{SEXUAL VIOLENCE PREVENTION IN REVIEW}

Breitenbecher's (2000) review of recent rape prevention efforts highlights the overall effectiveness of many sexual violence prevention programs and lessons learned about best practices. For example, research points to the importance of changing attitudes of both men and women as key antecedents to unwanted sexual experiences (e.g., Cowan, 2000; O'Donohue, Yeater, \& Fanetti, 2003), the efficacy of single-sex groups for programming, the importance of using peer leaders, and the need to use active learning strategies. Rape prevention curricula have also been criticized for focusing too much on individuals, small groups such as athletes or fraternity members, or criminal justice policies rather than wider social change (e.g., Potter, Krider, \& McMahon, 2000; Swift \& Ryan-Finn, 1995). In addition, many programs do not show persistence of effects over time or have not been carefully empirically evaluated, and thus their effectiveness is unclear. Finally, questions remain about what constitutes a sufficient dose of programming, with research showing the greatest effects for semesterlong educational programs that may be difficult to implement throughout communities (e.g., Flores \& Hartlaub, 1998). Schewe and O'Donohue's (1993) review of rape prevention specifically also highlights ways in which many programs focus on rape avoidance and may be directly or indirectly victim-blaming. Indeed, many traditional programs focus mainly on men as potential perpetrators and women as potential victims.

\section{THE BYSTANDER APPROACH}

One innovation is the use of a bystander approach to the widespread problem of sexual violence prevention across campuses and other communities (e.g., Banyard, Plante, \& Moynihan, 2004; Berkowitz, 2002; DeKeseredy, Schwartz, \& Alvi, 2000; Foubert, 2000; Foubert \& Marriott, 1997; Katz, 1994; Slaby \& Stringham, 1994). This approach involves teaching bystanders how to intervene in situations that involve sexual violence. While still involving programming that trains groups of individuals, this model takes next steps toward a broader community approach to prevention. The bystander model gives all community members a specific role, which they can identify with and adopt in preventing the community problem of sexual violence. This role includes interrupting situations that could lead to assault before it happens or during an incident, speaking out against social norms that support sexual violence, and having skills to be an effective and supportive ally to survivors. It is based on studies that point to the role of community norms as a significant cause of sexual violence, particularly in communities like college campuses (Schwartz \& DeKeseredy, 1997, 2000). 
Foubert (2000), DeKeseredy et al. (2000), and Berkowitz (2003) look at the role of bystanders in relation to sexual violence prevention and have focused on the effectiveness of the approach specifically for men. The Mentors in Violence Prevention (MVP) program (Katz, 1994) has evaluated a program using a nonexperimental prepost design that trains leaders among high-school-aged men and women and was effective in changing attitudes about creating social change around the broader problem of gender violence (Ward, 2001). Yet to date there has been little study of programs that embed an understanding of bystander behavior within a broader community responsibility paradigm useful for a primary prevention approach.

\section{CURRENT STUDY}

The purpose of the current study was to evaluate the effectiveness of a sexual violence prevention program based on preventing antecedents to sexual violence by increasing prosocial bystander behavior as outlined by Banyard et al. (2004). The program was administered in single-sex groups as recommended by the rape prevention literature (e.g., Breitenbecher, 2000). The longitudinal phase of the study compared students who did and did not receive one of two versions of the program on measures of knowledge and attitudes about sexual assault, efficacy related to being an active bystander, and actual bystander behaviors. Two versions of the program were developed and tested to compare the effectiveness of different doses of the intervention, a key question in the practical realm of widespread implementation (e.g., Nation et al., 2003). Analyses of gender differences in the effectiveness of the program were also conducted.

The first hypothesis states that participants who received one of two forms of the prevention program would show an increase in outcome measures of knowledge, attitudes, and behaviors from pretest prior to participation in the prevention program to posttest following the prevention program, while the control group would not. We hypothesized that these differences would persist at 2, 4, and 12 months following the administration of the prevention program. We also hypothesized that the program would work for both men and women in changing attitudes and behaviors, decreasing attitudes that support rape culture and increasing attitudes and behaviors that promote support for survivors and community responsibility for change.

\section{PROGRAM DESGRIPTION}

As stated above, two versions of the program were developed and assessed in consultation with practitioners in the field. These members of a statewide coalition on domestic and sexual violence and staff at local crisis centers discussed with researchers the limited resources, particularly in terms of time, for conducting prevention programming. As a result, two doses of the program were developed, both short enough to fit within what practitioners described as the realistic constraints of programming in their community.

\section{Control Group}

Participants in this group received no prevention program. They attended a pretest session during which they completed a questionnaire. Approximately 2 weeks later they returned to complete the same questionnaire again. At this time they were given a list of campus resources including the counseling center and rape crisis center. They 
were recontacted 2 months later to again complete the questionnaire. The subset of students from the first year of the study was eligible for the 12-month follow-up and those in the second year of the study were eligible for the 4-month follow-up.

\section{One-Session Prevention Program}

Participants in this group attended one 90-minute prevention program. A team of one male and one female peer leader conducted the single-sex groups. (These facilitators were students at the university trained in the prevention program.) Program content covered basic information about prevalence, causes, and consequences of sexual violence as well as discussions of how community members can play important prevention roles as bystanders observing risky situations before and during acts of sexual violence (e.g., observing a very intoxicated person being led into a bedroom at a party by a group of people) and afterward if approached by a friend who discloses that they have been a victim. Active learning exercises including role plays were used to help participants think about how they might intervene safely and be a supportive ally to survivors. Particular emphasis was placed on participants' own safety and on using resources such as campus police and rape crisis center resources. Participants were asked to generate a "bystander plan" and to sign a pledge (both of which they were asked to keep) that they would be active, prosocial bystanders in the community.

\section{Three-Session Prevention Program}

Participants in these groups attended three 90-minute sessions of the prevention program during one week using a similar format and expanded content from the single 90-minute program. Again, a pair of peer leaders (one male and one female) led single-sex groups of participants.

\section{Booster Session}

An additional component to the program was a booster session administered 2 months after the prevention program. The larger prevention literature is replete with examples that show the importance of follow-up programming "to support durability of impact" (e.g., Nation et al., 2003, p. 452). Participants in the treatment groups were put into small, 30-minute discussion groups of no more than 25 participants. These discussion groups were shown a 5-minute videotaped skit performed by a campus theater troupe depicting a survivor of sexual assault asking for help from several individuals with blindfolds who refuse to see or hear her. Following this, the facilitator led participants in an open-ended 20-minute discussion about what they remembered from the prevention program.

\section{METHOD}

\section{Participants}

In order to qualify as a participant an individual had to be a university undergraduate student between the ages of 18 and 23 who had never been trained as a sexual violence advocate at the university or other similar program elsewhere. All participants were paid for their time. 
Three hundred and eighty-nine undergraduates (217 women and 172 men) filled out pretest questionnaires. Table 1 presents the numbers of participants for each wave of data collection and retention rates. The research was conducted in two waves during each of two successive academic years because of constraints of both the funding for this project (2 years) and the academic calendar, in which students are available on campus only certain months of the year. Participants in both waves received questionnaires at pretest, posttest, and 2-month follow-up. There were no differences between participants in the two waves of data on sex, year in school, or pretest measures; therefore, data from all participants for pretest, posttest, and 2-month analyses were pooled and analyzed together as a single sample. Data collection was impacted by using two waves of data collection in the length of time we were able to follow participants. Only participants in the first session of data collection were eligible for a 12-month follow-up within the time constraints of the project, while participants during the second year of the study were eligible for a 4-month follow-up. These data points were examined separately and only in an exploratory manner because of the decreased sample size.

At pretest $55.8 \%$ of the participants were women; the mean age of all participants was $19.4 ; 38.3 \%$ were first-year students, $29.4 \%$ were sophomores, $19.8 \%$ were juniors, and $12.4 \%$ were seniors. The sample was overwhelmingly white: $90.4 \%$ (based on a total $N$ of 334 because of problems with missing data on this variable), although that is representative of the population at the university. Chi-square and t-test analyses showed that there were no significant differences between groups on gender, age, year in school, or ethnicity at pretest, posttest, 2-month, or 4-month follow-ups. More women than men returned to be part of the 12-month follow-up. There were also no significant differences between pretest demographics and those of the sample at the follow-up time points with the exception of gender at 12 months.

\section{PROCEDURES}

Participants were recruited both through flyers posted around the campus area and through a recruitment table in the student union building. Upon contact with researchers, a participant's eligibility was determined and the individual was then randomly assigned to one of the three groups.

\section{MEASURES}

\section{Outcome Measures}

Outcome measures at pretest, posttest, and 2- and 4- or 12-month follow-up consisted of the same set of measures that included assessment of knowledge, attitudes, and behavior. Some measures were created for this research study because few instruments exist to measure bystander attitudes and behavior in relation to sexual violence. All measures created for the study were developed and refined through pilot testing prior to being used in the current study. The pilot test included reliability and validity checks and focus groups. In addition, the control group in the current study can be used to examine test-retest reliability of measures when examining correlations for participants from pre- to posttest. These are reported below. All Cronbach's alphas reported below are for the full sample at pretest. 


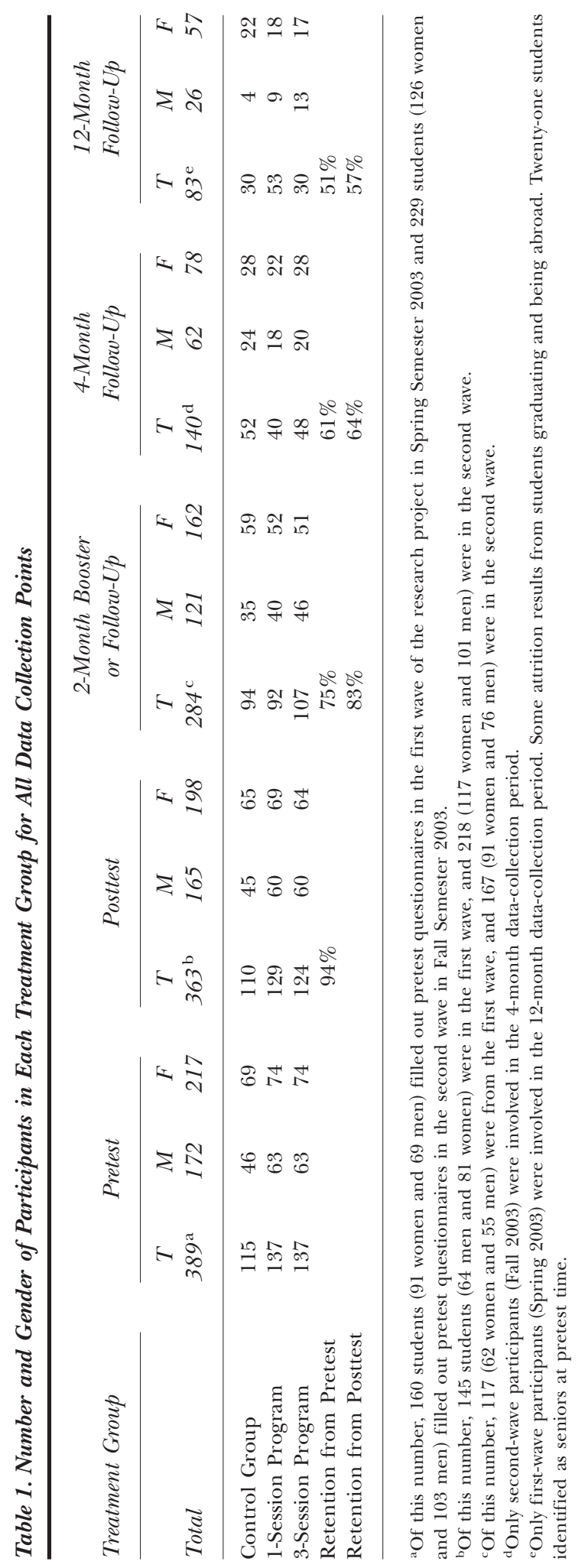


Knowledge assessment (Banyard, Plante, E Moynihan, 2005). To assess knowledge, 10 items were developed for use with this project including multiple-choice and shortanswer items. Four of the items had multiple parts. For example, "According to the campus Student Code of Conduct, sexual misconduct includes any sexual activity as defined by __ circle all that are correct." This was followed by a list of 13 statements. Participants obtained a score for each of the 13 statements depending on whether they correctly identified it as part of the student code of conduct or not part of the code. This resulted in 43 possible question items. Participants were scored with either " 0 " for an incorrect response or " 1 " for a correct response. Scores were based on knowledge imparted during the prevention program and modeled after the method of Lonsway and Kothari (2000) who describe the use of such knowledge-based questions in their evaluation of a program for first-year college students. Higher scores indicate greater numbers of correct responses. The Cronbach's alpha was 0.84 $(M=17.04, S D=6.12$ with a range from 0 to 31$)$. Nineteen participants had missing data on this scale. Pretest to posttest correlations for the control group were 0.76 .

\section{Attitudes}

Several measures of attitudes related to sexual violence and willingness to help were also used as outcome measures.

Illinois Rape Myth Acceptance Scale-Short Form (Payne, Lonsway, E Fitzgerald, 1999). This is a 20-item scale developed to assess participants' endorsement of a variety of common myths about sexual assault. (Three items are filler items and not used in calculating scores.) Participants indicated on a seven-point Likert scale the extent to which they agree with each item. For example, "Women tend to exaggerate how much rape affects them." Higher scores indicate greater acceptance or endorsement of rape myths. The Cronbach's alpha was $0.83(M=32.90, S D=11.36$ with a range from 17 to 95$)$. Twenty-three participants had missing data on this scale. This scale has demonstrated adequate reliability and validity in studies by the scale's authors (Payne et al.).

College Date Rape Attitude Survey (Lanier E Elliott, 1997). This measure consists of 20 items assessing attitudes related to date rape. It has been used in a modified form by Schultz, Scherman, and Marshall (2000) to assess behavioral change among students participating in a rape prevention program. Students indicate their agreement with each of the 20 statements using a five-point scale. For example, "Many women pretend they don't want to have sex because they don't want to appear 'easy." In contrast to the Illinois Rape Myth scale, higher scores on this scale indicate greater disagreement with date rape myths. The Cronbach's alpha was $0.92(M=76.59, S D=15.33$ with a range from 26 to 98). Fourteen participants had missing data on this scale. This scale has demonstrated adequate reliability and validity in its use in a variety of previous studies (e.g. Lanier \& Elliott).

Bystander attitudes (Banyard, Plante, Eं Moynihan, 2005). A list of 51 potential bystander helping behaviors was generated for this project from examples in the literature as well as from discussions with advocates and professionals working in the field of sexual violence, the pilot study, and formative evaluation with a sample of college students. Participants were asked to respond on a five-point scale how willing or likely they 
would be to engage in that bystanding behavior. For example, "How likely are you to investigate if you are awakened at night by someone calling for help?" Scores were created by summing responses across the items. Higher scores indicate greater willingness to engage in prosocial bystander behaviors. The Cronbach's alpha was 0.94 $(M=198.17, S D=27.77$ with a range from 73 to 255$)$. Forty-five participants had missing data on this scale. For the control group, the correlation from pre- to posttest was 0.86 .

Bystander behaviors (Banyard, Plante, E् Moynihan, 2005). Using the same list of behaviors as in the attitude scale above, a second scale was created. Participants were asked to answer yes or no to indicate behaviors in which they had actually engaged during the last 2 months. For example, "Have you walked a friend home from a party who has had too much to drink?" Again, scores were obtained by summing the number of behaviors they reported having done. The Cronbach's alpha was $0.89(M=10.02$, $S D=6.48$ with a range from 0 to 45 ). Thirty-two participants had missing data on this scale. Given that this scale measures actual behaviors, which we might expect to vary extensively over time, the pre- to posttest correlation for the control group was only 0.38 .

Bystander efficacy scale (Banyard, Plante, E Moynihan, 2005). This scale was also developed for this project. It was modeled on work by LaPlant (2002) in her development of academic and eating self-efficacy scales and grounded in measures used in the broader self-efficacy literature. Again, pilot testing was used to develop the measure, which showed adequate reliability and correlated with other measures of bystander efficacy in relation to broader questions of violence prevention (e.g., Slaby, WilsonBrewer, \& DeVos, 1994). Participants were asked to indicate their confidence, on a scale of 0 "can't do" to 100 "very certain can do," in performing each of 14 bystanding behaviors. For example, "How confident are you that you could ask a stranger who looks very upset at a party if they are ok or need help?" Scores were created by subtracting the mean of these 14 items from 100 to create a scale of perceived ineffectiveness; thus, higher scores indicate lesser effectiveness. The Cronbach's alpha was $0.87(M=20.55, S D=14.19$ with a range from 0 to 92.86$)$. None of the participants had missing data on this scale. Control group pre- to posttest correlation on this measure was 0.81 .

Decisional balance scale (Banyard, Plante, $\mathcal{E}$ Moynihan, 2005). The bystander literature often discusses decisions that individuals must make, weighing the pros and cons before deciding to intervene. Thus, participants were asked to complete a questionnaire developed for this research and based on Prochaska and DiClemente's transtheoretical model of health behavior change (Grimley, Prochaska, Velicer, Blais, \& DiClemente, 1994), which has been discussed as potentially important in sexual assault prevention (Berkowitz, 2002). Measures of decisional balance (the pros and cons of changing behavior) have been developed for a variety of health behaviors including exercise, weight loss, and decreased use of substances. Based on these measures we developed a "decisional balance scale" in relation to bystanding behaviors. This was an 11-item scale reflecting both positive benefits and negative consequences for intervening "in a situation where you thought someone might be being hurt or was at risk of being hurt." For example, "If I intervene regularly, I can prevent someone from being hurt" or "Intervening might cost me friendships." Responses were given on a 
five-point scale ranging from "not at all important" to "extremely important" in deciding whether or not to intervene. A subscale score for positive or pro attitudes consisted of items such as "If I intervene regularly I can prevent someone from being hurt." The negative or cons subscale consisted of six statements about negative consequences of bystander intervention. A total decisional balance score was obtained by subtracting the "cons" score from the "pros" score. Thus, higher scores indicate greater perceptions of positive aspects of bystander behavior when compared to negative aspects. The Cronbach's alpha was $0.69(M=1.04, S D=5.79$ with a range from -20 to 19). Three participants had missing data. The correlation for the control group from pre- to posttest was 0.67 .

\section{Assessing Individual Differences Among Participants}

Demographics. Participants were asked a number of demographic questions including age, year in school, and sex. Other background questions and additional measures of personality were also included but are not used in the current analyses and so are not described here.

Social desirability (Crowne $\mathcal{E}^{2}$ Marlowe, 1960). This is a 33-item measure to assess a socially desirable response bias among participants. This was used to assess the degree to which participants respond to the research instruments in socially desirable ways and to statistically control for it. Participants indicate whether each of the 33 statements is "true or false in terms of their own behavior," and responses are summed for a total score. Higher scores indicate higher socially desirable patterns of responding. The Cronbach's alpha was $0.75(M=17.98, S D=4.96$ with a range from 4 to 31$)$. Thirteen participants had missing data on this scale. This is a widely used measure of social desirability with demonstrated reliability and validity in previous studies.

\section{RESULTS}

\section{Preliminary Data Screening}

Overall, there was very little missing data for participants who completed each questionnaire. Missing data were dealt with by using the mean function to compute scores on each of the measures as the mean response across all items for that individual participant, provided that responses were given to the majority of items. Mean scores were then multiplied by the number of items in the scale to arrive at units of measurement reflective of scores obtained by simply adding all items in the scale together. Table 2 presents descriptive statistics for all outcome measures across the five time points of the study.

To verify that the three groups did not differ significantly on any of the variables prior to the intervention, multivariate analysis of variance (MANOVA) was first used to test for differences among all three groups on the outcomes at pretest. The experimental group was the independent variable. Overall, the main effect for the experimental group on pretest scores was not significant $F(14,758)=0.56$ and Wilks' Lambda was 0.98 . Thus, the groups did not significantly differ from one another on outcome measures at pretest.

To assess the relationship between socially desirable bias in responding and outcomes, a series of Pearson correlations were performed between scores on the Marlow- 
Table 2. Means (SDs) for Outcome Measures by Group and Time

\begin{tabular}{|c|c|c|c|c|c|c|}
\hline \multirow[b]{3}{*}{$\mathrm{N}$} & \multicolumn{3}{|c|}{ Pretest } & \multicolumn{3}{|c|}{ Posttest } \\
\hline & Control & 1 Session & 3 Sessions & Control & 1 Session & 3 Sessions \\
\hline & 115 & 137 & 137 & $108-110$ & $128-129$ & $123-124$ \\
\hline \multicolumn{7}{|l|}{ Measure } \\
\hline Efficacy & $20.58(14.01)$ & $20.76(14.79)$ & $20.40(13.80)$ & $20.06(15.03)$ & $13.20(11.86)$ & $10.60(9.79)$ \\
\hline Knowledge & $16.39(6.33)$ & $17.29(5.70)$ & $17.34(6.35)$ & $16.06(6.65)$ & $20.09(5.67)$ & $24.51(4.66)$ \\
\hline \multicolumn{7}{|l|}{ Rape myth acceptance } \\
\hline Illinois Rape Myth & $32.54(12.65)$ & $32.20(12.84)$ & $32.90(11.18)$ & $31.40(12.08)$ & $28.38(11.44)$ & $25.76(7.61)$ \\
\hline Date Rape Myth & $76.40(15.82)$ & $77.98(13.52)$ & $75.50(16.00)$ & $78.96(13.00)$ & $81.70(14.98)$ & $82.87(15.40)$ \\
\hline Bystander attitudes & $197.95(27.88)$ & $199.54(27.81)$ & $196.30(27.02)$ & $199.24(29.42)$ & $215.97(25.16)$ & $219.82(24.40)$ \\
\hline Bystander behavior & $9.58(6.29)$ & $10.47(6.41)$ & $10.06(6.84)$ & not measured & not measured & not measured \\
\hline \multirow[t]{3}{*}{ Decisional balance } & $0.97(6.07)$ & $1.19(5.85)$ & $0.93(5.52)$ & $-0.54(6.32)$ & $3.81(5.77)$ & $3.90(6.57)$ \\
\hline & \multicolumn{3}{|c|}{2 Month } & & & \\
\hline & Control & 1 Session & 3 Sessions & & & \\
\hline $\mathrm{N}$ & $93-94$ & $92-93$ & 97 & & & \\
\hline \multicolumn{7}{|l|}{ Measure } \\
\hline Efficacy & $20.10(15.98)$ & $13.21(10.19)$ & $12.54(10.26)$ & & & \\
\hline Knowledge & $16.95(7.16)$ & $19.91(5.68)$ & $27.17(11.26)$ & & & \\
\hline \multicolumn{7}{|l|}{ Rape myth acceptance } \\
\hline Illinois Rape Myth & $30.09(11.90)$ & $27.79(11.73)$ & $27.17(11.26)$ & & & \\
\hline Date Rape Myth & $80.81(11.55)$ & $83.48(11.09)$ & $83.49(13.21)$ & & & \\
\hline Bystander attitudes & $201.85(28.77)$ & $15.35(24.28)$ & $214.34(26.13)$ & & & \\
\hline Bystander behavior & $11.57(6.34)$ & $14.72(8.66)$ & $12.70(6.78)$ & & & \\
\hline \multirow[t]{3}{*}{ Decisional balance } & $-0.02(5.37)$ & $2.25(6.16)$ & $3.75(6.31)$ & & & \\
\hline & \multicolumn{3}{|c|}{4 Month } & \multicolumn{3}{|c|}{12 Month } \\
\hline & Control & 1 Session & 3 Sessions & Control & 1 Session & 3 Sessions \\
\hline $\mathrm{N}$ & $51-52$ & 40 & 48 & 26 & 27 & 30 \\
\hline \multicolumn{7}{|l|}{ Measure } \\
\hline Efficacy & $21.20(16.99)$ & $14.28(10.36)$ & $13.56(11.09)$ & $21.90(16.44)$ & $13.12(10.79)$ & $13.58(14.01)$ \\
\hline Knowledge & $16.42(7.86)$ & $19.03(5.39)$ & $22.31(5.35)$ & $18.58(7.06)$ & $19.70(5.22)$ & $23.23(4.67)$ \\
\hline \multicolumn{7}{|l|}{ Rape myth acceptance } \\
\hline Illinois Rape Myth & $38.84(15.86)$ & $34.38(16.47)$ & $31.03(11.49)$ & $33.94(13.40)$ & $28.36(8.83)$ & $33.53(11.92)$ \\
\hline Date Rape Myth & $77.94(12.94)$ & $83.35(14.66)$ & $83.31(12.82)$ & $82.42(15.31)$ & $85.37(13.32)$ & $81.40(15.83)$ \\
\hline Bystander attitudes & $197.62(30.79)$ & $212.44(23.66)$ & $213.66(25.59)$ & $207.85(27.38)$ & $213.06(27.58)$ & $211.11(23.14)$ \\
\hline Bystander behavior & $11.16(6.83)$ & $14.12(6.53)$ & $11.02(4.68)$ & $12.88(6.92)$ & $13.93(6.50)$ & $12.80(7.22)$ \\
\hline Decisional balance & $-1.85(6.34)$ & $2.43(5.63)$ & $2.83(6.45)$ & $-1.27(5.33)$ & $3.56(5.93)$ & $3.17(6.70)$ \\
\hline
\end{tabular}

Crowne Social Desirability measure and outcomes at posttest. Table 3 presents these findings. A number of outcomes including Illinois Rape Myth Acceptance scale, expressed willingness to engage in bystander behaviors, bystander efficacy, and total decisional balance scores were correlated with the measure of social desirability. Social desirability was used in further analyses as a covariate.

Finally, intercorrelations among outcome measures were computed for all participants at pretest to establish the independence of outcome measures from one another. Table 3 presents these results. Higher perceived bystander ineffectiveness was related to lower bystander willingness to intervene and more negative perceptions of bystanding. Otherwise, correlations were fairly low between measures, supporting the decision 
Table 3. Intercorrelations Between Outcome Measures at Pretest $(N=389)$

\begin{tabular}{|c|c|c|c|c|c|c|c|}
\hline Variable & 1 & 2 & 3 & 4 & 5 & 6 & 7 \\
\hline 1. Knowledge & - & $-0.14^{*}$ & 0.09 & $0.21 * * *$ & $0.23 * * *$ & $-0.11 *$ & $0.12 *$ \\
\hline 2. Illinois Rape Myth & & - & $-0.40 * * *$ & $-0.32 * * *$ & $-0.12^{*}$ & $0.24 * * *$ & $-0.21 * * *$ \\
\hline 3. Date Rape Myth & & & - & $0.22 * * *$ & 0.07 & -0.08 & 0.05 \\
\hline 4. Helping attitudes & & & & - & $0.37 * * *$ & $-0.70 * * *$ & $0.41 * * *$ \\
\hline 5. Helping behavior & & & & & - & $-0.30 * * *$ & $0.19 * * *$ \\
\hline 6. Bystander efficacy & & & & & & - & $-0.41 * * *$ \\
\hline 7. Decisional balance & & & & & & & - \\
\hline 8. Social desirability $(N=388)$ & -0.05 & $0.13^{* *}$ & $-0.15^{* *}$ & $-0.28 * * *$ & -0.01 & $0.21 * * *$ & $-0.26 * * *$ \\
\hline
\end{tabular}

$* p<0.05, * * p<0.01, * * * p<0.001$, two-tailed significance.

to use this range of outcomes. Of particular note is that the measure of bystanding attitudes was only correlated 0.37 with actual bystander behavior, supporting the use of these two measures as discrete outcomes.

\section{Testing Intervention Impact}

The first hypothesis stated that there would be significant effects of the prevention program. From pretest to posttest, both treatment groups were expected to show increased scores on bystander efficacy, significant increases in knowledge, decreased acceptance of rape myths, increased expressed willingness to help, and increases in the actual numbers of bystander behaviors engaged in. Treatment groups were expected to score higher on appreciation of the "pros" versus "cons" in relation to being an active prosocial bystander.

A repeated measures multiple analysis of covariance (MANCOVA) was performed. Experimental group (no program, one-session program, and three-session program) and gender served as the independent variables with six outcome variables. (Actual bystander behavior was not used because it was only measured again at the 2-month follow-up session; results for this measure are presented later.) Three time pointspretest, posttest, and 2-month follow-up-were assessed. As noted above, scores on the Marlow-Crowne Social Desirability Scale were used as a covariate. Overall, there were significant effects for social desirability $[F(6,270)=4.69, p<0.001$, Wilks' Lambda $=$ $0.91]$, for treatment group $[F(12,540)=6.32, p<0.001$, Wilks' Lambda $=0.77]$, and for $\operatorname{sex}[F(6,270)=14.00, p<0.001$, Wilks' Lambda $=0.76]$. There was no significant group by sex interaction. There was no significant within-subject effect for time. There was a significant within-subject interaction effect for time by social desirability $[F(12,264)=1.84, p<0.05$, Wilks' Lambda $=0.92]$.

Most importantly, and of relevance to the first hypothesis, there was a significant time by group interaction when social desirability was controlled ${ }^{1}[F(24,528)=6.84$, $p<0.001$, Wilks' Lambda $=0.58]$. Indeed, $42 \%$ of the variance in scores on outcomes was explained by differences between the experimental groups over time. There was also a significant time by sex interaction $[F(12,264)=2.35, p<0.01$, Wilks' Lambda $=$ $0.90]$, though the time by group by sex interaction was not significant. Univariate

\footnotetext{
${ }^{1}$ It should be noted here that these same analyses were performed using only pre- and posttest data (thus data are not confounded by the presence of the 2-month booster) with identical results to those presented here. The MANCOVA for three time points is presented here for the sake of brevity.
} 
Table 4. MANOVA of Pretest-Posttest Difference Scores $(N=356)$

\begin{tabular}{lcccc}
\hline Outcome & Control & 1 Session & 3 Sessions & $\mathrm{F}(2,353)$ \\
\hline Efficacy & $-0.47(9.11)^{\mathrm{a}}$ & $-7.32(11.10)^{\mathrm{b}}$ & $-10.08(13.22)^{\mathrm{b}}$ & $21.76^{* * * *}$ \\
Knowledge & $-0.13(4.47)^{\mathrm{a}}$ & $2.85(4.68)^{\mathrm{b}}$ & $7.19(6.32)^{\mathrm{c}}$ & $57.80^{* * *}$ \\
Rape myth acceptance & & & & \\
$\quad$ & & $-7.56(8.66)^{\mathrm{b}}$ & $-7.67(8.33)^{\mathrm{c}}$ & $18.54^{* * *}$ \\
Illinois Rape Myth & $-1.11(7.48)^{\mathrm{a}}$ & $3.76(14.61)$ & $8.31(17.07)^{\mathrm{b}}$ & $4.90^{* *}$ \\
Date Rape Myth & $2.20(15.18)^{\mathrm{a}}$ & $15.60(19.49)^{\mathrm{b}}$ & $24.37(22.08)^{\mathrm{c}}$ & $42.49^{* * *}$ \\
Bystander attitudes & $1.15(15.26)^{\mathrm{a}}$ & $2.45(5.08)^{\mathrm{b}}$ & $3.08(5.91)^{\mathrm{b}}$ & $24.93^{* * *}$ \\
Decisional balance & $-1.53(5.08)^{\mathrm{a}}$ & & & \\
\hline
\end{tabular}

Note. Superscripts indicate group differences on Tukey's post-hoc tests from univariate analyses.

$* * p<0.01, * * * p<0.001$, two-tailed significance.

analyses revealed significant time by group interactions on all outcomes, with the highest effect sizes (partial eta squared) for gains in knowledge (0.14), positive helping attitudes (0.10), and bystander efficacy (0.08).

To examine these findings in more detail, a MANOVA was performed using difference scores from pretest to posttest as the dependent variables and experimental group as the independent variable $[F(12,706)=18.45, p<0.001$, Wilks' Lambda $=$ 0.58]. Post-hoc tests using Tukey's HSD test were performed to examine betweengroup differences in difference scores. Table 4 presents these findings. Of note is the pattern of results showing differences between the control group and treatment groups for all measures. There were also significant differences between the one- and threesession groups, with the group that received the more lengthy program showing greater increases in knowledge and positive bystander attitudes, and lower rape myth acceptance than participants in the one-session group.

Finally, we performed a series of paired sample t-tests to unpack changes in scores across the three groups. Table 5 presents these results. Overall, both treatment groups showed changes in scores in the expected directions (greater efficacy, knowledge, willingness to help, and appreciation of "pros" of helping, and lower rape myth acceptance) while the control group did not. On one measure, the control group did show significant change in their scores (decisional balance), though this change was in the

Table 5. Paired Sample t-Tests for Pretest to Posttest for Each Group

\begin{tabular}{lccc}
\hline & \multicolumn{3}{c}{$t$} \\
\cline { 2 - 4 } & Control & 1 Session & 3 Sessions \\
Outcome & $(\mathrm{N}=108-110)$ & $(\mathrm{N}=128-129)$ & $(\mathrm{N}=123-124)$ \\
\hline Efficacy & 0.60 & $7.54 * * *$ & $8.49 * * *$ \\
Knowledge & 0.51 & $-6.86 * * *$ & $-12.67 * * *$ \\
Rape myth acceptance & & & $10.25 * * *$ \\
Illinois Rape Myth & 1.66 & $6.07 * * *$ & $-5.42 * * *$ \\
$\quad$ Date Rape Myth & -1.51 & $-2.91 * *$ & $-12.29 * * *$ \\
Bystander attitudes & -0.85 & $-5.09 * * *$ & $-5.80 * * *$ \\
Decisional balance & $3.23 * *$ & & \\
\hline
\end{tabular}

$* * p<0.01, * * * p<0.001$, two-tailed significance. 
Table 6. Paired Sample t-Tests for Pretest to 2 Months for Each Group

\begin{tabular}{lccc}
\hline & \multicolumn{3}{c}{$t$} \\
\cline { 2 - 4 } & $\begin{array}{c}\text { Control } \\
\text { Outcome }\end{array}$ & $\begin{array}{c}1 \text { Session } \\
(\mathrm{N}=94)\end{array}$ & $\begin{array}{c}3 \text { Sessions } \\
(\mathrm{N}=96-93)\end{array}$ \\
\hline Efficacy & -0.08 & $5.98^{* * *}$ & $5.65^{* * *}$ \\
Knowledge & & & $-9.15^{* * *}$ \\
$\quad$ Total score & -0.34 & $-4.96^{* * *}$ & $5.05^{* * *}$ \\
Rape myth acceptance & & $4.64^{* * *}$ & $-5.33^{* * *}$ \\
$\quad$ Illinois Rape Myth & $2.84^{* *}$ & $-4.43^{* * *}$ & $-7.94^{* * *}$ \\
$\quad$ Date Rape Myth & $-2.01^{*}$ & $-7.92^{* * *}$ & $-3.94^{* * *}$ \\
Bystander attitudes & -1.94 & $-5.68^{* * *}$ & $-4.21^{* * *}$ \\
Bystander behavior & $-2.85^{* *}$ & $-2.50^{*}$ & \\
Decisional balance & 1.84 & & \\
\hline
\end{tabular}

$* p<0.05, * * p<0.01, * * * p<0.001$, two-tailed significance.

opposite direction of the treatment groups (i.e., for the control group perception of cons related to bystander intervention increased). To limit the risk of Type I error, Bonferroni corrections were also computed. The revised alpha level was 0.008 , indicating that all of the analyses remained significant except the change in date rape myth acceptance for the one-session program group.

A series of paired sample t-tests were also performed examining differences for each experimental group from pretest to 2 months. Table 6 presents these results. It should be noted again that changes on some measures for the control group were in the opposite direction from those found for the treatment groups. The treatment effects did persist from short term to longer term follow-up. To limit the risk of Type I error, Bonferroni corrections were also computed. The revised alpha level (0.002) indicates that all of the analyses remained significant for the treatment group except the change in decisional balance for the one-session treatment group. With the Bonferroni correction, changes in control group scores became nonsignificant.

Finally, at the 2-month follow-up, further data were collected about actual bystander behavior. A repeated-measures MANCOVA was performed examining change over time from pretest to 2-month follow-up on the behavioral measure using social desirability as a covariate. There was a significant main effect of time $[F(1,276)=12.21, p=$ 0.001 , Wilks' Lambda $=0.96]$ and for the time by group interaction $[F(2,276)=3.54$, $p<0.05$, Wilks' Lambda $=0.98]$, but no significant time by social desirability interaction, time by sex interaction, or time by group by sex interaction. Follow-up paired sample t-tests revealed that all three groups showed increases in reported bystander behavior from pretest to 2 months. These findings are shown in Table 6. An analysis of covariance (ANCOVA) using difference scores on the behavioral measure as the outcome, and social desirability as the covariate, showed a significant effect of group $[F(2,279)=4.31, p=0.01]$. The treatment groups had higher increases in reported bystander behavior than the control group.

\section{Understanding Gender}

As stated earlier, although there was a main effect for sex, there were no significant time by group by sex interactions for the MANCOVAs performed to assess program 
Table 7. MANCOVA for Pretest Outcome Scores by Gender Including Means (SDs) with Social Desirability as Covariate $(N=387)$

\begin{tabular}{|c|c|c|c|}
\hline Outcome & $\begin{array}{c}\text { Male } \\
\mathrm{N}=171\end{array}$ & $\begin{array}{c}\text { Female } \\
\mathrm{N}=217\end{array}$ & $\mathrm{~F}(1,384)$ \\
\hline Efficacy & $20.69(15.07)$ & $20.53(13.53)$ & 0.03 \\
\hline Knowledge & $16.05(6.48)$ & $17.84(5.74)$ & $8.36 * *$ \\
\hline \multicolumn{4}{|l|}{ Rape myth acceptance } \\
\hline Illinois Rape Myth & $37.48(13.56)$ & $29.17(9.52)$ & $51.49 * * *$ \\
\hline Date Rape Myth & $73.08(13.53)$ & $79.46(15.79)$ & $18.41 * * *$ \\
\hline Bystander attitudes & $191.27(29.52)$ & $203.33(24.71)$ & $21.49 * * *$ \\
\hline Bystander behavior & $8.42(5.74)$ & $11.41(6.83)$ & $20.86 * * *$ \\
\hline Decisional balance & $1.87(6.01)$ & $.38(5.54)$ & $6.50 * *$ \\
\hline
\end{tabular}

$* * p<0.01, * * * p<0.001$, two-tailed significance.

effects. To investigate more carefully the main effect of gender, a MANCOVA was performed on pretest outcome measures for men and women using social desirability as a covariate. Table 7 presents these results. There was a significant main effect for social desirability $[F(7,379)=9.10, p<0.001$, Wilks' Lambda $=0.87]$ and for sex $[F(6,379)=19.31, p<0.001$, Wilks' Lambda $=0.77]$. Univariate analyses indicated sex differences on most outcomes, with women more knowledgeable, less endorsing of general rape myths, more accurate about date rape, and more willing to engage in various bystander behaviors. Women reported that they actually engaged in more bystander behaviors and had total decisional balance scores that reflected less positive views of being an active bystander. The lack of a significant group by time by sex interaction for either repeated measures MANCOVA suggests that for this sample, there were not overall significant differences between men and women in the impact of the prevention program.

\section{Four- and Twelve-Month Follow-Up}

An exploratory analysis was done with data from the 4- and 12-month follow-ups since sample sizes became much smaller for this data. It was hypothesized that changes from pretest scores for the two treatment groups would persist at 4- and 12-month followups such that these groups would continue to look significantly different from the control group. Paired sample t-tests were used to investigate changes in mean scores on outcome measures from pretest to 4 months. Table 8 presents these results. Again, note that any changes in control group scores were in a different direction from treatment group scores. To limit the risk of Type I error, Bonferroni corrections were also computed. The revised alpha level was 0.002 , indicating that most of the analyses remained significant.

One complication was that many more women than men returned for the 12-month follow-up. Given that women scored more favorably than men on many outcome measures across the time points, this demographic difference in samples from pretest to follow-ups may have had an impact on results. Thus, paired sample t-tests were computed from pretest to 12-month follow-up only for women because this may present a more accurate picture of the results. The results are presented in Table 9. Looking across outcome measures, there seem to be some persistent effects across time points 
Table 8. Paired Sample t-Tests for Pretest to 4 Months for Each Group

\begin{tabular}{|c|c|c|c|}
\hline \multirow[b]{2}{*}{ Outcome } & \multicolumn{3}{|c|}{$t$} \\
\hline & $\begin{array}{c}\text { Control } \\
\mathrm{N}=51-52\end{array}$ & $\begin{array}{l}1 \text { Session } \\
\mathrm{N}=40\end{array}$ & $\begin{array}{c}3 \text { Sessions } \\
\mathrm{N}=48\end{array}$ \\
\hline Efficacy & -1.27 & $3.02 * *$ & $4.19 * * *$ \\
\hline \multicolumn{4}{|l|}{ Knowledge } \\
\hline Total score & -0.36 & $-2.63 * *$ & $-7.37 * * *$ \\
\hline \multicolumn{4}{|l|}{ Rape myth acceptance } \\
\hline Illinois Rape Myth & $-4.32 * *$ & -0.61 & 1.50 \\
\hline Date Rape Myth & -1.43 & $-4.51 * * *$ & $-3.22 * *$ \\
\hline Bystander attitudes & -1.40 & $-2.92 * *$ & $-5.48 * * *$ \\
\hline Bystander behavior & -1.85 & $-3.14 * *$ & -0.26 \\
\hline Decisional balance & $3.49 * * *$ & -1.76 & -1.10 \\
\hline
\end{tabular}

$* * p<0.01, * * * p<0.001$, two-tailed significance.

in that participants in the treatment groups continue to show improved scores on most outcome measures as compared to control participants. Using a Bonferroni correction of 0.007 , it was found that only knowledge and rape myths show persistent changes for the treatment groups. However, reported significance levels are for the more conservative two-tailed test. Given the experimental hypotheses, a one-tailed test could have been used resulting in improved significance.

\section{DISCUSSION}

The current study demonstrated the utility of using a bystander approach to sexual violence prevention. Although earlier studies have discussed this approach (e.g., Berkowitz, 2001) and evaluated its effectiveness for men (e.g., Foubert \& Mariott, 1997), to our knowledge this is the first experimental evaluation of such a program using a

Table 9. Paired Sample t-Tests for Pretest to 12 Months for Each Group for Women Only

\begin{tabular}{lccc}
\hline & \multicolumn{3}{c}{$t$} \\
\cline { 2 - 4 } & $\begin{array}{c}\text { Control } \\
\text { Outcome }\end{array}$ & $\begin{array}{c}\text { 1 Session } \\
\mathrm{N}=22\end{array}$ & $\begin{array}{c}\text { 3 Sessions } \\
\mathrm{N}=18\end{array}$ \\
\hline Efficacy & 0.12 & $4.20^{* * *}$ & $2.20^{*}$ \\
Knowledge & & & $-3.15^{* *}$ \\
$\quad$ Total score & -0.75 & -1.52 & 0.40 \\
Rape myth acceptance & & $2.88^{* *}$ & $-2.43^{*}$ \\
$\quad$ Illinois Rape Myth & $-2.94^{* *}$ & -1.00 & $-2.49^{*}$ \\
$\quad$ Date Rape Myth & 0.61 & -1.93 & -1.37 \\
Bystander attitudes & -1.07 & $-2.81^{* *}$ & $-2.22^{*}$ \\
Bystander behavior & -0.94 & & \\
Decisional balance & 1.27 & & \\
\hline
\end{tabular}

$* p<0.05, * * p<0.01, * * * p<0.001$, two-tailed significance. 
large sample of both men and women. Participants in both the one- and three-session prevention program groups showed improvement across outcome measures from pretest to posttest as compared to control group participants. This finding is consistent with previous studies using other models of rape prevention (e.g., Anderson, Stoelb, Duggan, Hieger, Kling, \& Payne, 1998; Heppner et al., 1995; Lanier \& Elliott, 1998; Lonsway \& Kothari, 2000; Pinzone-Glover et al., 1998). These effects were seen across outcome measures typically assessed in rape prevention evaluation research, including decrease in rape myth acceptance and increased knowledge of sexual violence. In addition, the current study found significant increases in prosocial bystander attitudes, increased bystander efficacy, and increases in self-reported bystander behaviors. Furthermore, both one-session and three-session doses produced significant changes, though more significant change was seen with the longer prevention program. Application of such results supports implementation of longer prevention programs when possible for maximum effect, but also suggests that when time constraints prohibit longer programs, even a shorter bystander program can create important changes.

Results of the current program seem to show persistence of effects over a somewhat longer time than some other programs (e.g., Yeater \& O'Donohue, 1999, for a review). In the current study, the persistence of effects at 2 months is likely due in part to the brief booster session given at that time that consisted of a brief discussion of what participants remembered from the program. Indeed, some effects of the program did seem to decline somewhat by the 4- and 12-month follow-ups, though for the treatment groups there were still many outcomes related to efficacy, knowledge, and attitudes that remained significant. Results were more mixed for bystander behavior, where significant effects were found for posttest and 2-month follow-ups but not more long term. In part this may have to do with when the follow-up for 4 - and 12-month participants occurred, early in the semester following a time when students were on semester break and may have had fewer opportunities to intervene as bystanders. Few studies within the sexual violence prevention literature have followed participants for up to one year, and the effects of this study are encouraging though in need of further study.

Results from the gender analyses suggest that the program benefited both male and female participants. Consistent with past research, women at pretest overall had higher scores on measures such as knowledge of sexual assault and lower rape myth acceptance than men (e.g., Muir, Lonsway, \& Payne, 1996). However, large effect sizes for the intervention were found for both men and women, consistent with past research highlighting the importance of such things as attitude change for both women and men (e.g., Cowan, 2000; O'Donohue et al., 2003).

There are a number of limitations to the current study. In particular, given the short duration of the grant that funded the study, long-term follow-up of all participants was not possible. Thus, data from 4- and 12-month time points had much smaller sample sizes than other time points, which may have impacted findings. The current sample is racially and ethnically homogeneous. There may be different issues related to bystander intervention for students of color, particularly if there are only small numbers of such students on campus. This is a key issue for further study: What are the facets of the actual larger community environment that may hamper or enhance prosocial bystanding related to sexual violence? Experimental demand is likely another large limitation to the current study. Though the study was advertised as a study of relationship and community problems, it was likely quite clear to all participants involved that we were studying views about sexual violence. 
Additionally, given the relatively recent use of a bystander approach in actual prevention program evaluation, there exist few instruments to carefully and thoroughly assess bystander attitudes and behavior and their correlates. This is an important direction for future research. Future studies must also take on the difficult issue of examining the relationship between antecedents of sexual violence such as bystander behavior and the actual incidence of sexual assault.

In spite of such limitations, however, the current study adds important information to those working in violence prevention settings. It represents one of the few experimental evaluations of a sexual violence prevention program and the only experimental study of prevention using a bystander model for both men and women currently in the empirical literature. These findings fit with Schewe and O'Donohue's (1996) recommendations to move beyond more traditional programming that blames victims and approaches men as perpetrators and women as victims. It also fits with Lonsway's (1996) call to develop prevention programs grounded in social psychological literature on attitude change.

\section{REFERENCES}

Acierno, R., Brady, K., Gray, M., Kilpatrick, D., Resnick, H., \& Best, C.L. (2001). Psychopathology following interpersonal violence: A comparison of risk factors in older and younger adults. Journal of Clinical Geropsychology, 8, 13-23.

Anderson, L.A., Stoelb, M.P., Duggan, P., Heiger, B., Kling, K.H., \& Payne, J.P. (1998). The effectiveness of two types of rape prevention programs in changing the rape-supportive attitudes of college students. Journal of College Student Development, 39, 131-142.

Banyard, V.L., Plante, E.G., \& Moynihan, M.M. (2004). Bystander education: Bringing a broader community perspective to sexual violence prevention. Journal of Community Psychology, $32,61-79$.

Banyard, V.L., Plante, E.G., \& Moynihan, M.M. (2005). Rape prevention through bystander education: Final report to NIJ for grant 2002-WG-BX-0009. Retrieved January 31, 2007, from www.ncjrs.org/pdffiles1/nij/grants/208701.pdf

Banyard, V.L., Plante, E., Ward, S., Cohn, E.S., Moorhead, C., \& Walsh, W. (2005). Revisiting unwanted sexual experiences on campus: A 12 year follow-up. Violence Against Women, 11, $426-446$.

Banyard, V.L., Williams, L.M., \& Siegel, J.A. (2001). The long-term mental health consequences of child sexual abuse: An exploratory study of the impact of multiple traumas in a sample of women. Journal of Traummatic Stress, 14, 697-715.

Berkowitz, A.D. (2001). Critical elements of sexual-assault prevention and risk-reduction programs for men and women. In C. Kilmartin \& A.D. Berkowitz (Eds.), Sexual assault in context (pp. 75-96). Mahwah, NJ: Lawrence Erlbaum.

Berkowitz, A.D. (2002). Fostering men's responsibility for preventing sexual assault. In P.A. Schewe (Ed.), Preventing violence in relationships: Interventions across the lifespan (pp. 163196). Washington, DC: American Psychological Association.

Berkowitz, A.D. (2003). Applications of social norms theory to other health and social justice issues. In W. Perkins (Ed.), The social norms approach to preventing school and college age substance abuse: A handbook for educators, counselors, and clinicians (pp. 259-279). San Francisco, CA: Jossey-Bass.

Brener, N.D., McMahon, P.M., Warren, C.W., \& Douglas, K.A. (1999). Forced sexual intercourse and associated health-risk behaviors among female college students in the United States. Journal of Consulting and Clinical Psychology, 67, 252-259. 
Breitenbecher, K.H. (2000). Sexual assault on college campuses: Is an ounce of prevention enough? Applied and Preventive Psychology, 9, 23-52.

Campbell, J., \& Soeken, K.L. (1999). Forced sex and intimate partner violence: Effects on women's risk and women's health. Violence Against Women, 5, 1017-1035.

Cowan, G. (2000). Women's hostility toward women and rape and sexual harassment myths. Violence Against Women, 6, 238-247.

Crowne, D.P., \& Marlowe, D. (1960). A new scale of social desirability independent of psychopathology. Journal of Consulting Psychology, 24, 349-354.

DeKeseredy, W.S., Schwartz, M.D., \& Alvi, S. (2000). The role of profeminist men in dealing with women on the Canadian college campus. Violence Against Women, 6, 918-935.

Fisher, B.S., Cullen, F.T., \& Turner, M.G. (2000). The sexual victimization of college women. Research Report to National Institute of Justice (NIJ 182369), Washington, D.C.

Flores, S.A., \& Hartlaub, M.G. (1998). Reducing rape-myth acceptance in male college students: A meta-analysis of intervention studies. Journal of College Student Development, 39, 438-448.

Foubert, J.D. (2000). The longitudinal effects of a rape-prevention program on fraternity men's attitudes, behavioral intent, and behavior. Journal of American College Health, 48, 158-163.

Foubert, J.D., \& Marriott, K.A. (1997). Effects of a sexual assault peer education program on men's beliefs in rape myths. Sex Roles, 36, 259-268.

Foubert, J.D., \& McEwen, M.K. (1998). An all-male rape prevention peer education program: Decreasing fraternity men's behavioral intent to rape. Journal of College Student Development, 39, 548-556.

Grimley, D., Prochaska, J.O., Velicer, W.F., Blais, L.M., \& DiClemente, C.C. (1994). The transtheoretical model of change. In T.M. Brinthaupt \& R.P. Lipka (Eds.), Changing the self: Philosophies, techniques, and experiences (pp. 201-227). Albany, NY: SUNY.

Heppner, M.J., Humphrey, C.F., Hillenbrand-Gunn, T.L., \& Debord, K.A. (1995). The differential effects of rape prevention programming on attitudes, behavior, and knowledge. Journal of Counseling Psychology, 42, 508-518.

Himelein, M.J. (1995). Risk factors for sexual victimization in dating: A longitudinal study of college women. Psychology of Women Quarterly, 19, 31-48.

Katz, J. (1994). Mentors in Violence Prevention (MVP) trainer's guide. Northeastern University's Center for the Study of Sport in Society. Boston, MA.

Koss, M.P., Gidycz, C.A., \& Wisniewski, N. (1987). The scope of rape: Incidence and prevalence of sexual aggression and victimization in a national sample of higher education students. Journal of Consulting and Clinical Psychology, 55, 162-170.

Lanier, C.A., \& Elliott, M.N. (1997). A new instrument for the evaluation of a date rape prevention program. Journal of College Student Development, 38, 673-676.

Lanier, C.A., Elliott, M.N., Martin, D.W., \& Kapadia, A. (1998). Evaluation of an intervention to change attitudes toward date rape. Journal of American College Health, 46, 177-180

LaPlant, L.E. (2002). Implementation and evaluation of group-based prevention of eating concerns using self-efficacy and knowledge enhancement. (Doctoral dissertation, University of New Hampshire, 2002). Dissertation Abstracts International, 63, 1609.

Lonsway, K.A. (1996). Preventing acquaintance rape through education: What do we know? Psychology of Women Quarterly, 20, 229-265.

Lonsway, K.A., \& Kothari, C. (2000). First year campus acquaintance rape education. Psychology of Women Quarterly, 24, 220-232.

Muir, G., Lonsway, K.A., \& Payne, D.L. (1996). Rape myth acceptance among Scottish and American students. Journal of Social Psychology, 136, 261-262. 
Nation, M., Crusto, C., Wandersman, A., Kumpfer, K.L., Seybolt, D., Morrissey-Kane, E., et al. (2003). What works in prevention: Principles of effective prevention programs. American Psychologist, 58, 449-456.

O’Donohue, W., Yeater, E.A., \& Fanetti, M. (2003). Rape prevention with college males: The roles of rape myth acceptance, victim empathy, and outcome expectancies. Journal of Interpersonal Violence, 18, 513-531.

Payne, D.L., Lonsway, K.A., \& Fitzgerald, L.F. (1999). Rape myth acceptance: Exploration of its structure and its measurement using the Illinois Rape Myth Acceptance Scale. Journal of Research in Personality, 33, 27-68.

Pinzone-Glover, H.A., Gidycz, C.A., \& Jacobs, C.D. (1998). An acquaintance rape prevention program: Effects on attitudes toward women, rape-related attitudes, and perceptions of rape scenarios. Psychology of Women Quarterly, 22, 605-621.

Potter, R.H., Krider, J.E., \& McMahon, P.M. (2000). Examining elements of campus sexual violence policies. Violence Against Women, 6, 1345-1362.

Schewe, P.A., \& O'Donohue, W. (1993). Rape prevention: Methodological problems and new directions. Clinical Psychology Review, 13, 667-682.

Schewe, P.A., \& O’Donohue, W. (1996). Rape prevention with high-risk males: Short-term outcome of two interventions. Archives of Sexual Behavior, 25, 455-471.

Schultz, S.K., Scherman, A., \& Marshall, L.J. (2000). Evaluation of a university-based date rape prevention program: Effect on attitudes and behavior related to rape. Journal of College Student Development, 41, 193-201.

Schwartz. M.D., \& DeKeseredy, W.S. (1997). Sexual assault on the college campus: The role of male peer support. Thousand Oaks, CA: Sage.

Schwartz, M.D., \& DeKeseredy, W.S. (2000). Aggregation bias and woman abuse: Variations by male peer support, region, language, and school type. Journal of Interpersonal Violence, $15,555-565$.

Slaby, R.G., \& Stringham, P. (1994). Prevention of peer and community violence: The pediatrician's role. Pediatrics, 94, 608-616.

Slaby, R., Wilson-Brewer, R., \& DeVos, H. (1994). Final report for Aggressors, Victims, and Bystanders Project (Final report of Grant No. R49/CCR 103559). Atlanta, GA: Centers for Disease Control and Prevention.

Swift, C.F., \& Ryan-Finn, K. (1995). Perpetrator prevention: Stopping the development of sexually abusive behavior. In C.F. Swift (Ed.), Sexual assault and abuse: Sociocultural context of prevention (pp. 13-44). New York: Haworth Press.

Ward, K.J. (2001). Mentors in Violence Prevention Program evaluation 1999-2000. Unpublished report, Northeastern University. Boston, MA.

Yeater, E.A., \& O'Donohue, W. (1999). Sexual assault prevention programs: Current issues, future directions, and the potential efficacy of interventions with women. Clinical Psychology Review, 19, 739-771. 